Article

\title{
Investigation of the Amide Linkages on Cooperative Supramolecular Polymerization of Organoplatinum(II) Complexes
}

\author{
Mingliang Gui, Yifei Han, Hua Zhong, Rui Liao * and Feng Wang *
}

Citation: Gui, M.; Han, Y.; Zhong, H.; Liao, R.; Wang, F. Investigation of the Amide Linkages on Cooperative Supramolecular Polymerization of Organoplatinum(II) Complexes. Molecules 2021, 26, 2832. https://doi. org/10.3390/molecules26092832

Academic Editor: Susana Ibáñez Maella

Received: 30 March 2021

Accepted: 14 April 2021

Published: 10 May 2021

Publisher's Note: MDPI stays neutral with regard to jurisdictional claims in published maps and institutional affiliations.

Copyright: (c) 2021 by the authors. Licensee MDPI, Basel, Switzerland. This article is an open access article distributed under the terms and conditions of the Creative Commons Attribution (CC BY) license (https:// creativecommons.org/licenses/by/ $4.0 /)$.
CAS Key Laboratory of Soft Matter Chemistry, Department of Polymer Science and Engineering, University of Science and Technology of China, Hefei 230026, China; gml0809@mail.ustc.edu.cn (M.G.); 15200828166@163.com (Y.H.); zh199901@mail.ustc.edu.cn (H.Z.)

* Correspondence: rliao@ustc.edu.cn (R.L.); drfwang@ustc.edu.cn (F.W.)

\begin{abstract}
Cooperative supramolecular polymerization of $\pi$-conjugated compounds into one-dimensional nanostructures has received tremendous attentions in recent years. It is commonly achieved by incorporating amide linkages into the monomeric structures, which provide hydrogen bonds for intermolecular non-covalent complexation. Herein, the effect of amide linkages is elaborately studied, by comparing supramolecular polymerization behaviors of two structurally similar monomers with the same platinum(II) acetylide cores. As compared to the $N$-phenyl benzamide linkages, $N$-[(1S)-1phenylethyl] benzamide linkages give rise to effective chirality transfer behaviors due to the closer distances between the chiral units and the platinum(II) acetylide core. They also provide stronger intermolecular hydrogen bonding strength, which consequently brings higher thermo-stability and enhanced gelation capability for the resulting supramolecular polymers. Supramolecular polymerization is further strengthened by varying the monomers from monotopic to ditopic structures. Hence, with the judicious modulation of structural parameters, the current study opens up new avenues for the rational design of supramolecular polymeric systems.
\end{abstract}

Keywords: supramolecular polymers; cooperativity; chirality; hydrogen bonds; organoplatinum(II) complexes; self-assembly

\section{Introduction}

Supramolecular polymerization of $\pi$-conjugated molecules has become an important way to access dynamic functional materials [1-6]. To achieve control over the size and shape of the resulting nanostructures, it is important to elucidate the supramolecular polymerization mechanism. Depending on the energy evolution of the supramolecular polymerization processes, three different types of mechanisms, namely isodesmic, cooperative, and anti-cooperative mechanisms, have been clarified $[7,8]$. The cooperative supramolecular polymerization mechanism, undergoing an initial nucleation step followed by the energetically favorable elongation stage, prevents the formation of small-sized oligomers commonly encountered in the isodesmic and anti-cooperative mechanisms. Moreover, by avoiding the spontaneous nucleation process, living supramolecular polymerization can be achieved on the basis of such cooperative assembled systems, thus providing new avenues toward highly-ordered supramolecular homopolymers and block copolymers [9-12]. Meriting from all these advantages, great efforts have been devoted to develop $\pi$-conjugated supramolecular polymeric systems with the cooperative mechanism. A plausible approach to attain this objective is to embed amide or urea units on the outside of $\pi$-conjugated cores. It facilitates the incorporation of intermolecular hydrogen bonds between the neighboring monomers, and thereby induces electronic cooperativity during the supramolecular polymerization process [13-17]. By adopting this principle, a variety of $\pi$-conjugated moieties such as arenes, oligo(phenylene ethynylene)s (OPEs), perylene bisimides (PBIs), porphyrins have been reported to form cooperative supramolecular polymers [18-30]. 
Organoplatinum(II) complexes are regarded as an intriguing type of $\pi$-conjugated compounds [31-34]. The presence of heavy metal not only increases $\pi$-conjugation length, but strengthens spin-orbit coupling with the neighboring ligands, thus endowing organoplatinum(II) complexes with fascinating photoelectrical properties [35-37]. More importantly, thanks to the square planar geometry of the $d^{8}$ transition metal ion, organoplatinum(II) structures are prone to aggregate with each other by means of $\pi-\pi$ stacking and/or metalmetal interactions $[38,39]$. Our research group has incorporated amides on both ends of platinum(II) acetylide rods (a typical structure is (S)-1 shown in Scheme 1) [40], which demonstrate the adoption of two-stage nucleation-elongation mechanism for the supramolecular polymerization process. By taking advantage of high molecular weight, ease of processability and strong emission properties for these supramolecular polymers, we have further demonstrated their applications in optical waveguide and anti-counterfeiting materials [41-43].



Scheme 1. Schematic representation for supramolecular polymerization of platinum(II) acetylides $(S)-\mathbf{1}$ and $(S)-\mathbf{2}$ with different properties.

In the previous organoplatinum(II)-based supramolecular systems [41-43], intermolecular hydrogen bonds are formed on the basis of $N$-phenylbenzamide linkages. Herein, a novel platinum(II) acetylide monomer (S)-2 has been designed (Scheme 1) and synthesized (Scheme 2), which contains two $\mathrm{N}$-[(1S)-1-phenylethyl]benzamide linkages. We envisage that the structural variations might influence intermolecular hydrogen bonding strength As a consequence, distinct supramolecular polymerization behaviors occur between the two structurally similar monomers $(S)-\mathbf{1}$ and $(S)-\mathbf{2}$. Another interesting point for $(S)-\mathbf{2}$ is the simultaneous incorporation of chiral methyl fragments into the amide linkages, which facilitates to the formation of single-handed chiral supramolecular polymers. As compared to those of (S)-1, the chiral units of (S)-2 move closer to the platinum(II) acetylide core, and thereby result in stronger chirality transfer capabilities. Accordingly, the elaborate manipulation of structural parameters at molecular level opens up new avenues for the rational construction of supramolecular polymeric systems. 

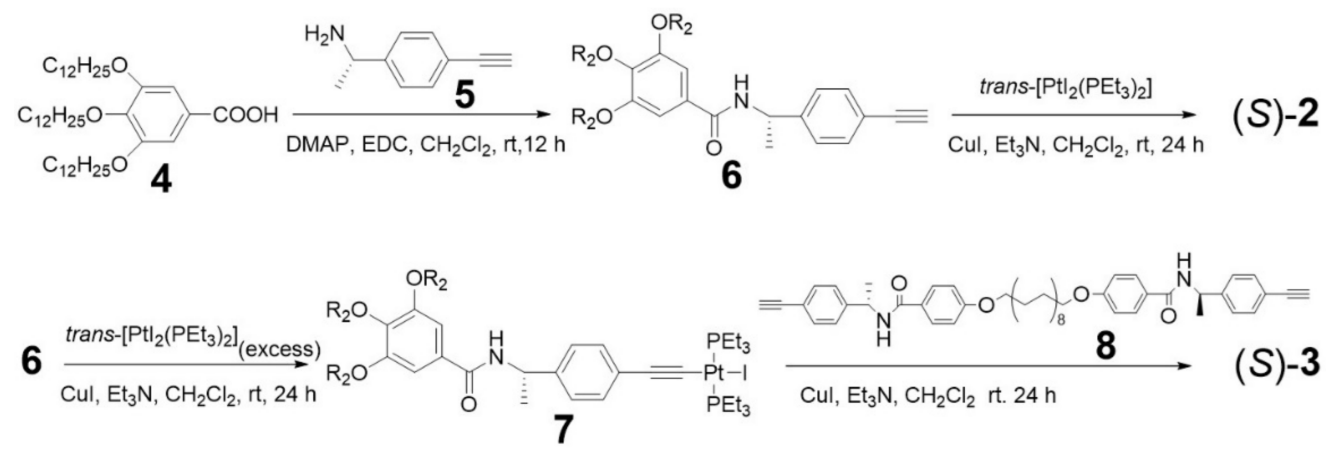

Scheme 2. Synthetic routes toward the platinum(II) acetylides (S)-2 and (S)-3.

\section{Results}

\subsection{Supramolecular Polymerization Behaviors of (S)-2 in Apolar Media}

As a first step, supramolecular assembly of monomer (S)-2 in apolar methylcyclohexane $\left(\mathrm{c}=4.00 \times 10^{-5} \mathrm{~mol} / \mathrm{L}, \mathrm{MCH}\right)$ was studied through UV-Vis and circular dichroism (CD) spectroscopy. At $323 \mathrm{~K}$, it exhibited a high-energy absorbance band between 250 and $307 \mathrm{~nm}\left(\lambda_{\max }: 265 \mathrm{~nm}, \varepsilon=5.10 \times 10^{4} \mathrm{~L} \mathrm{~cm}^{-1} \mathrm{~mol}^{-1}\right)$, together with a low-energy absorption band between 310 and $368 \mathrm{~nm}\left(\lambda_{\max }: 335 \mathrm{~nm}, \varepsilon=3.18 \times 10^{4} \mathrm{~L} \mathrm{~cm}^{-1} \mathrm{~mol}^{-1}\right.$, Figure 1a). According to the previous literature, the former band corresponds to $\pi-\pi^{*}$ transition of the chiral N-[(1S)-1-phenylethyl] benzamide moieties [44]. Meanwhile, the latter band is assigned to $\mathrm{PEt}_{3}$-based intra-ligand (IL) $\pi-\pi^{*}$ transition, together with some admixture of metal d orbitals $[45,46]$. In the CD spectrum, a very weak Cotton effect below $330 \mathrm{~nm}$ was observed at $323 \mathrm{~K}$, which derives from the intrinsic molecular chirality (Figure 1a). Accordingly, at high temperature (S)-2 is dominated by a molecularly dissolved state in apolar media.
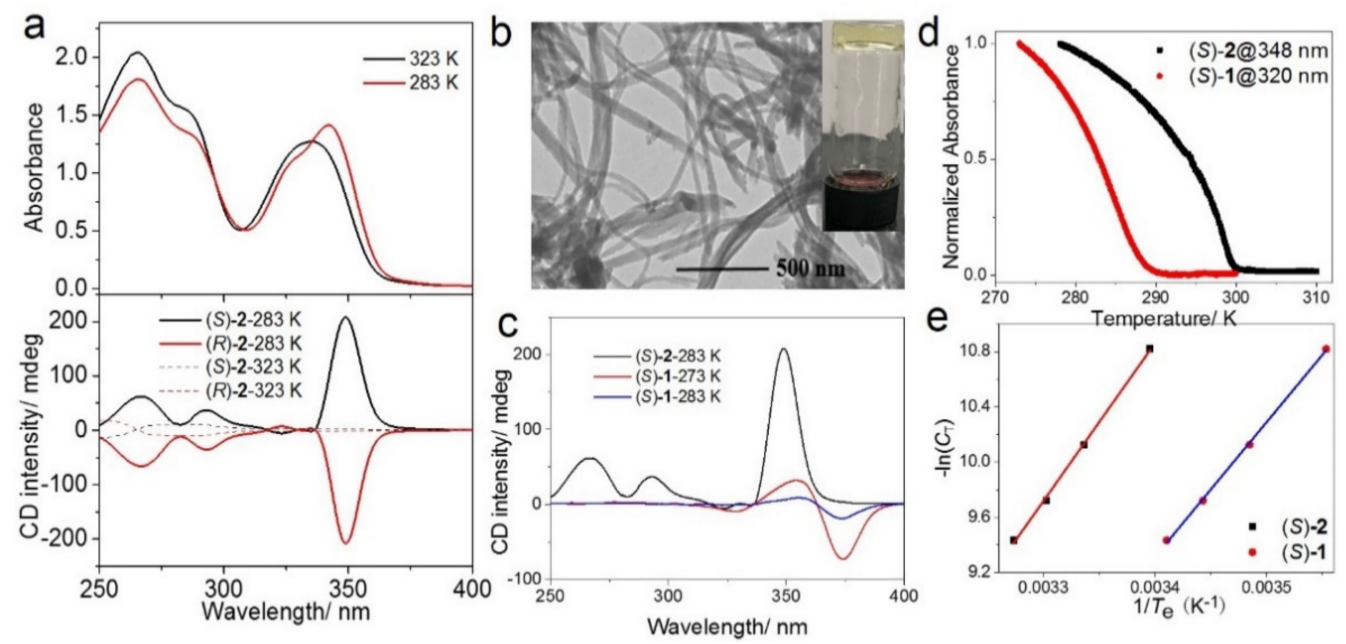

Figure 1. (a) upper, UV-Vis spectra of (S)-2 at $323 \mathrm{~K}$ (black line) and $283 \mathrm{~K}$ (red line); below, CD spectra of (S)-2 and (R)-2 at $323 \mathrm{~K}$ and $283 \mathrm{~K}(\mathrm{c}=0.04 \mathrm{mM}$ in $\mathrm{MCH})$. (b) TEM image (copper grid, $0.06 \mathrm{mM}$ ) of (S)-2. Inset: organogel of (S)-2 at the concentration of $11.0 \mathrm{mM}$ in MCH. (c) CD spectra $(\mathrm{c}=0.04 \mathrm{mM}$ in $\mathrm{MCH})$ of $(S)-2$ at $283 \mathrm{~K}$ (black line), together with $(S)-\mathbf{1}$ at $273 \mathrm{~K}$ (red line) and $283 \mathrm{~K}$ (blue line). (d) Normalized absorbance of (S)-1 and (S)-2 versus temperature upon cooling at a rate of $60 \mathrm{~K} \mathrm{~h}^{-1}$ in $\mathrm{MCH}(\mathrm{c}=0.04 \mathrm{mM})$. (e) Van't Hoff plots for $(S)-\mathbf{1}$ and $(S)-2$ in $\mathrm{MCH}$.

Upon lowering the temperature to $283 \mathrm{~K}$, a bathochromic shift was observed for the IL transition band $\left(\lambda_{\max }=342 \mathrm{~nm}\right.$, Figure 1a). Moreover, two isosbestic points exist at 298 and $335 \mathrm{~nm}$, suggesting the reversible transition between the monomeric and aggregated states of (S)-2 upon varying the temperature (Figure S1). In the meantime, obvious Cotton effects appeared for (S)-2 at the low-energy IL absorption region, with the positive maximum at 
$349 \mathrm{~nm}\left(\Delta \varepsilon=157 \mathrm{~L} \mathrm{~cm}^{-1} \mathrm{~mol}^{-1}, \mathrm{~g}=0.00623\right)$ (Figure 1a). Mirror imaged CD signals were observed for the enantiomer $(R)$-2 (Figure 1a). As widely documented, CD spectroscopy is a powerful technique to probe the regularity of the self-assembled chiral structures, since the induced $\mathrm{CD}$ signals are only present for long-range ordered assemblies yet absent for short-ranged oligomeric counterparts $[47,48]$. Accordingly, these experimental results validate chirality transfer from the $N-[(1 S)-1$-phenylethyl]benzamide linkages to the inner platinum(II) acetylide core, leading to the formation of single-handed supramolecular polymers at low temperature. It is worthy to note that the measured CD signals were real to reflect the supramolecular chirality, since no linear dichroism (LD) signals were detected under the same circumstances (Figure S2) [49]. The formation of long-range ordered supramolecular polymeric structures for (S)-2 was further demonstrated by transmission electron microscope (TEM) experiments, which showed the intertwined nanofibers with several microns in length and approximately $70 \mathrm{~nm}$ in width (Figure $1 \mathrm{~b}$ and Figure S3).

Interestingly, supramolecular chirality signals of (S)-2 differ from those of (S)-1. In particular, unlike the presence of postive CD signals for (S)-2, (S)-1 exhibited bisignate CD signals in the IL absorption region at $283 \mathrm{~K}$, with the positive maximum at $349 \mathrm{~nm}$ and the negative one at $323 \mathrm{~nm}$ (Figure 1c). Moreover, the Cotton effects of $(S)-\mathbf{1}$ were much lower than those of (S)-2, even cooling the MCH solution of (S)-1 to $273 \mathrm{~K}$ (at which point the monomers reach fully aggregated, vide infra) $\left(\Delta \varepsilon:-55.2 \mathrm{~L} \mathrm{~cm}^{-1} \mathrm{~mol}^{-1}\right.$ for $(S)-\mathbf{1}$ at 374 $\mathrm{nm}$ versus $157 \mathrm{~L} \mathrm{~cm}^{-1} \mathrm{~mol}^{-1}$ for (S)-2 at $349 \mathrm{~nm}$, Figure 1c). It is rationalized that (S)-2 features closer distances between the chiral (1S)-1-phenylethyl units and the platinum(II) acetylide rod. As a consequence, it gives rise to stronger capability for supramolecular chiralilty transfer. The results were similar to the previous BTA-based supramolecular systems reported by Meijer and coworkers, which exhibited strong CD signals when the peripherial chiral units move closer to the $\pi$-aromatic core [50].

\subsection{Comparison of Supramolecular Polymerization Thermodynamics between (S)-1 and (S)-2}

Deeper insights into the supramolecular polymerization behaviors of $(S)$-2 were achieved via temperature-dependent UV-Vis and CD experiments. Non-sigmoidal melting curves were obtained, by monitoring the absorption intensities at $348 \mathrm{~nm}$ (Figure 1d) and CD intensities at $350 \mathrm{~nm}$ (Figure S4) with the melting rate at $60 \mathrm{~K} \mathrm{~h}^{-1}$. The phenomena supported the adoption of cooperative nucleation-elongation mechanism for the supramolecular polymerization process. The normalized melting curves were further fitted by the Meijer-Schenning-Van der Schoot mathematical model (see Equation (1) in the Section 4) [51,52]. Depending on the UV-Vis melting curve, $T_{\mathrm{e}}$ (critical elongation temperature) value of (S)-2 was determined to be $299.7 \mathrm{~K}$ at the monomer concentration of $4.00 \times 10^{-5} \mathrm{~mol} / \mathrm{L}$ in $\mathrm{MCH}$ solution, while the $h_{\mathrm{e}}$ (enthalpy release upon elongation) value was $-96.5 \mathrm{~kJ} \mathrm{~mol}^{-1}$ (Figure $1 \mathrm{~d}$ and Figure S4). Similar values were obtained for the CD melting curve under the same circumstances $\left(T_{\mathrm{e}}: 298.7 \mathrm{~K}, h_{\mathrm{e}}:-93.5 \mathrm{~kJ} \mathrm{~mol}^{-1}\right.$, Figure $\left.\mathrm{S} 4\right)$. On this basis, the quantitative supramolecular polymerization parameters were acquired via the modified Van't Hoff plots (Figure 1e). As shown in Table 1, the enthalpy release $(\Delta H)$ value and the entropy release $(\Delta S)$ value were determined to be $-95.1 \mathrm{~kJ} \mathrm{~mol}^{-1}$ and $-233 \mathrm{~J} \mathrm{~mol}^{-1} \mathrm{~K}^{-1}$ in $\mathrm{MCH}$, giving rise to the Gibbs free energy $(\Delta G)$ value of $-26.8 \mathrm{~kJ} \mathrm{~mol}^{-1}$ at $293 \mathrm{~K}$ (Table 1, Figure S5).

Table 1. Thermodynamic Parameters Obtained by Fitting Temperature-Dependent UV-Vis data. ${ }^{a}$

\begin{tabular}{|c|c|c|c|c|c|}
\hline Compound & $T_{\mathrm{e}}(\mathrm{K})$ & $h_{\mathrm{e}}\left(\mathrm{kJ} \mathrm{mol}^{-1}\right)$ & $\Delta H\left(\mathrm{~kJ} \mathrm{~mol}^{-1}\right)$ & $\Delta S\left(\mathrm{~J} \mathrm{~mol}^{-1} \mathrm{~K}^{-1}\right)$ & $\Delta G\left(\mathrm{~kJ} \mathrm{~mol}^{-1}, 293 \mathrm{~K}\right)$ \\
\hline$(S)-\mathbf{1}$ & 287.0 & -129 & -81.0 & -198 & -22.9 \\
\hline$(S)-2$ & 299.7 & -96.5 & -95.1 & -233 & -26.8 \\
\hline
\end{tabular}

${ }^{a} \operatorname{In~} \mathrm{MCH}(c=0.04 \mathrm{mM})$. 
We have previously reported that supramolecular polymerization of (S)-1 also adopts nucleation-elongation cooperation mechanism. Nevertheless, the thermodynamic parameters of the two compounds are different. In particular, (S)-2 displays more negative $\Delta H$ and $\Delta G$ values than those of $(S)-1\left(\Delta H:-95.1 \mathrm{~kJ} \mathrm{~mol}^{-1}\right.$ vs. $-81.0 \mathrm{~kJ} \mathrm{~mol}^{-1} ; \Delta G:-26.8 \mathrm{~kJ}$ $\mathrm{mol}^{-1}$ vs. $-22.9 \mathrm{~kJ} \mathrm{~mol}^{-1}$ at $293 \mathrm{~K}$, Table 1, Figure S6). Accordingly, it indicates stronger non-covalent complexation strength for the former compound during the supramolecular polymerization process. Such properties consequently bring higher thermo-stability for supramolecular polymers, as evidenced by the increased $T_{\mathrm{e}}$ values [ $299.7 \mathrm{~K}$ for supramolecular polymers derived from (S)-2 vs. $287.0 \mathrm{~K}$ for those from (S)-1 at the concentration of $0.04 \mathrm{mM}$ in $\mathrm{MCH}$, Figure 1d]. Furthermore, (S)-2 displayed strong gelation capability in $\mathrm{MCH}$. The critical gelation concentration (CGC) of (S)-2 was $10.9 \mathrm{mM}$ at room temperature (Figure $1 \mathrm{~b}$, inset). According to the rheological experiments, the storage modulus $G^{\prime}$ and loss modulus $G^{\prime \prime}$ of $(S)-2$ gels in $\mathrm{MCH}$ were determined to be $4755 \mathrm{~Pa}$ and $713 \mathrm{~Pa}$, respectively (Figure S7). In sharp contrast, (S)-1 failed to gelate $\mathrm{MCH}$ at room temperature, and formed organogels in heptane with a higher CGC value $\left(37.0 \mathrm{mmol} \mathrm{L}^{-1}\right.$, Figure S7) [40].

The distinct properties between $(S)-\mathbf{1}$ and $(S)-\mathbf{2}$ emphasize the amide linkage effects on supramolecular polymerization behaviors. The reasonable explanation was achieved by density functional theory (DFT) computations. The $\mathrm{NH}-\mathrm{O}$ bond lengths between the neighboring amide units were determined to be $1.88 \AA$ and $1.89 \AA$ in $(S)-\mathbf{2}_{2}$, which were shorter than those of $(S)-\mathbf{1}_{2}(2.03 \AA$ and $2.02 \AA$, Figure 2$)$. Besides, the Gibbs free energy $(\Delta G)$ value of $(S)-\mathbf{2}_{2}$ was more negative than that of $(S)-\mathbf{1}_{2}\left(-159 \mathrm{~kJ} \mathrm{~mol}^{-1} \mathrm{vs} .-138 \mathrm{~kJ} \mathrm{~mol}^{-1}\right.$, Figure 2). Hence, intermolecular hydrogen-bond interactions of (S)-2 were stronger than those of (S)-1, which exert crucial impacts on the stability of supramolecular polymers. The participation of intermolecular hydrogen bonds in (S)-2 was further verified by means of ${ }^{1} \mathrm{H}$ NMR measurements (Figure S8), which showed downfield shift of $\mathrm{NH}$ protons upon increasing the monomer concentration (from $6.13 \mathrm{ppm}$ at $2.00 \mathrm{mM}$ to $6.19 \mathrm{ppm}$ at $30.0 \mathrm{mM}$ in deuterio-chloroform).
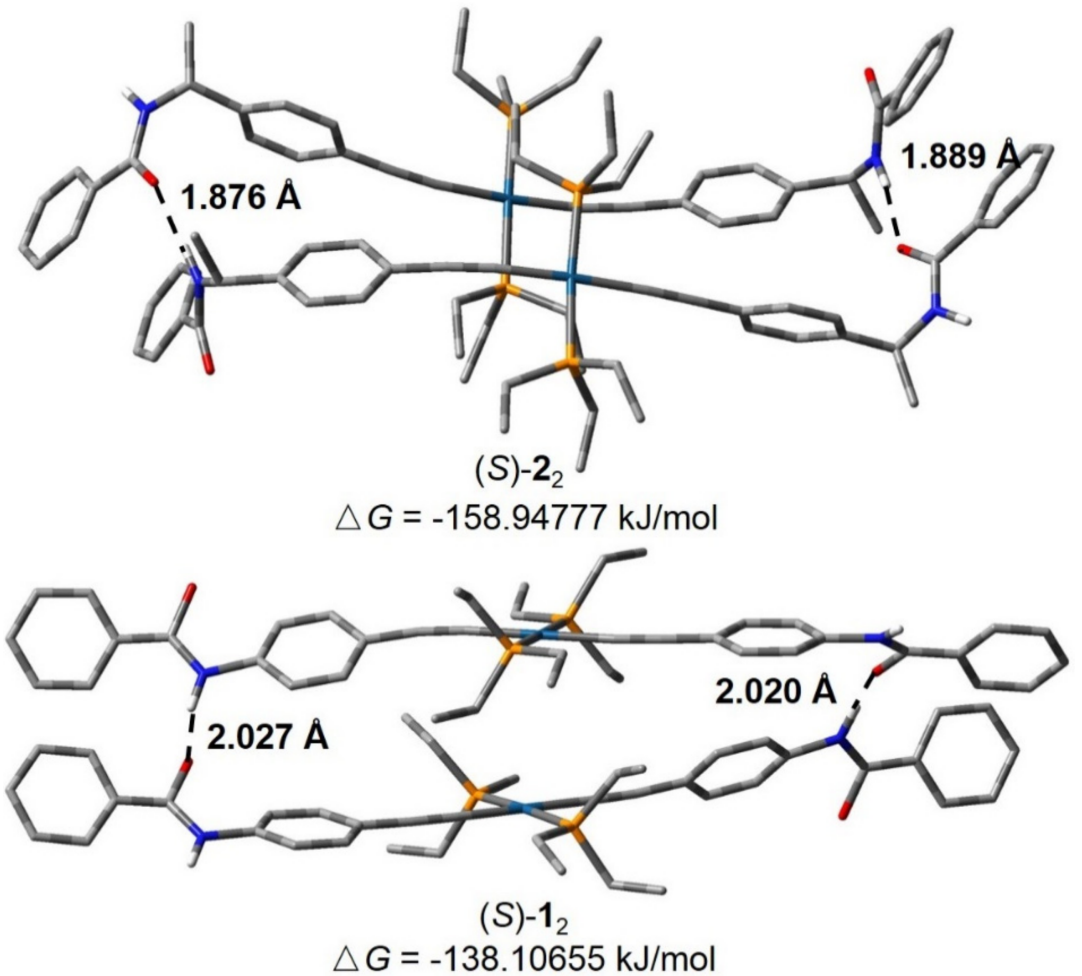

Figure 2. Optimized dimeric structures of $(S)-\mathbf{2}_{2}$ and (S)-1 $\mathbf{1}_{2}$ on the basis of DFT calculations. 


\subsection{Majority-Rules for Supramolecular Polymers Derived from (S)-2/(R)-2}

In supramolecular polymeric systems, chirality amplification is increasingly important for both fundamental science and practical applications [53-56]. It denotes the transfer of chiral information from molecular to supramolecular levels, in which "majority-rules" effects refer to the ability of a small enantiomeric imbalance to dictate the handedness of helical polymers [57-59]. With both (S)-2 and (R)-2 in hand, majority-rules experiments were performed by mixing the two enantiomers in different ratios at the total concentration of $4.00 \times 10^{-5} \mathrm{~mol} / \mathrm{L}$ at $293 \mathrm{~K}$. The full CD spectra showed the transition from pure $(R)-2$ $(e e=100 \%)$ through the $(S)-2 /(R)-2(1: 1)(e e=0 \%)$ to pure $(S)-2(e e=-100 \%)$ (Figure 3a). By probing the net helicity at $351 \mathrm{~nm}$ versus the ee values, an almost linear plot was obtained (Figure $3 b$ ), illustrating rather weak majority-rules effect for $(S)-\mathbf{2} /(R)-\mathbf{2}$. Accordingly, it reflected the strong homo-recognition between monomers $(S)-2$ and $(R)-2$, thus giving rise to narcissistic self-sorted supramolecular homopolymers. Additional evidence for the absence of hetero-complexation between $(S)-2$ and $(R)-2$ was deduced from the melting curves of $(S)-2 /(R)-2(e e=-50 \%)$ at a total concentration of $4.00 \times 10^{-5} \mathrm{~mol} / \mathrm{L}$. In particular, the elongation temperature $T_{\mathrm{e}}$ was determined to be $296.4 \mathrm{~K}$ (Figure S9). The value is lower than that of pure $(S)-2$ at $4.00 \times 10^{-5} \mathrm{~mol} / \mathrm{L}\left(T_{\mathrm{e}}=298.7 \mathrm{~K}\right.$, Figure S9), while similar to that of $(S)-2$ at $3.00 \times 10^{-5} \mathrm{~mol} / \mathrm{L}\left(T_{\mathrm{e}}=297.6 \mathrm{~K}\right.$, Figure S9). Therefore, it verified poor mixing capability for the opposite enantiomers, thus giving rise to self-sorted supramolecular homopolymers with low thermal stability.
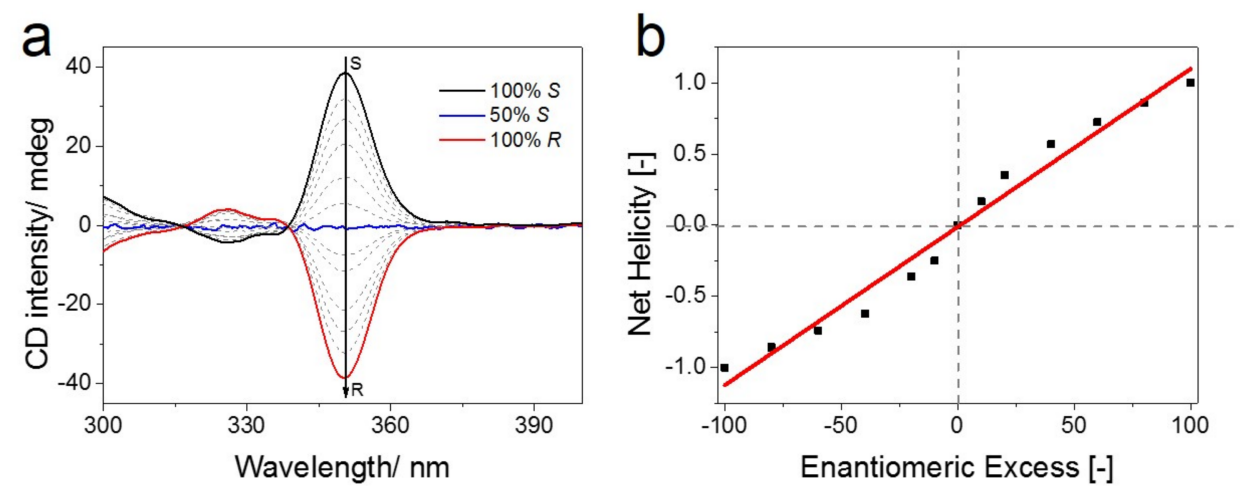

Figure 3. (a) CD spectra recorded at room temperature of mixtures of different $e e$ as indicated by the arrow from pure $(S)-2$ through $e e=0 \%(1: 1$ mixture) to pure $(R)-2$. $(\mathbf{b})$ The net helicity as function of the ee.

The absence of majority-rules effects has been previously reported in some supramolecular polymeric systems [60-62]. For example, Meijer's group developed zinc porphyrin-based supramolecular polymers with ( $S$ or R)-3,7-dimethyloctyl side chains on the monomeric structures. Ascribed to the presence of twelve methyl stereogenic centers, high structural mismatching exists. Consequently, a chiral monomer fails to incorporate into a stack of its opposite chirality, and ultimately gives rise to narcissistic self-sorting into conglomerate stacks. In the current system, structural mismatching also exists between the two enantiomers (S)-2 and (R)-2, despite the fact that only two methyl stereogenic centers are present in the monomeric structures. We envisaged that the $N$-[(1S)-1-phenylethyl] benzamide linkages impose large steric hindrance around the chiral centers, and thereby disfavors hetero-complexation between $(S)-2$ and $(R)-2$. Besides, the presence of large steric $\mathrm{Pt}\left(\mathrm{PEt}_{3}\right)_{2}$ unit might also decrease the likelihood of coaggregation between the opposite enantiomers.

\subsection{Supramolecular Polymerization Behaviors of (S)-3}

In addition to the monotopic monomer (S)-2, we also studied supramolecular polymerization behaviors of the ditopic monomer (S)-3. It is not soluble in pure $\mathrm{MCH}$. The phenomenon is ascribed to the presence of four amide units, which provide stronger aggregation tendency than that of (S)-2. In this regard, UV-Vis and CD spectroscopic 
measurements were performed for $(S)-3$ in MCH/TCE $\left(99: 1, v / v, c=2.00 \times 10^{-5} \mathrm{~mol} / \mathrm{L}\right)$. For UV-Vis spectrum of (S)-3 at $293 \mathrm{~K}$, it exhibited two absorption bands centered at 264 and $333 \mathrm{~nm}$, respectively (Figure S10), which were similar to those of (S)-2. Cotton effects were observed for $(S)-3$ in MCH/TCE $\left(99: 1, v / v, c=2.00 \times 10^{-5} \mathrm{~mol} / \mathrm{L}\right)$, with the positive maximum at $342 \mathrm{~nm}\left(\Delta \varepsilon=102 \mathrm{~L} \mathrm{~cm}^{-1} \mathrm{~mol}^{-1}, g=0.00314\right)$ and negative maximum at $321 \mathrm{~nm}\left(\Delta \varepsilon=-16.6 \mathrm{~L} \mathrm{~cm}^{-1} \mathrm{~mol}^{-1}, g=-0.000465\right)$ (Figure $\left.4 \mathrm{~b}\right)$. Depending on temperaturedependent CD measurements, a non-sigmoidal melting curve was obtained by monitoring the CD intensities at $342 \mathrm{~nm}$, supporting the adoption of nucleation-elongation cooperative mechanism (Figure S10). Notably, the $T_{\mathrm{e}}$ value of (S)-3 was determined to be $302.8 \mathrm{~K}$ (Figure 4c), which was significantly higher than the $T_{\mathrm{e}}$ value of $(S)-2(290.4 \mathrm{~K})$ at the same amounts of platinum acetylide units $\left(\mathrm{MCH} / \mathrm{TCE}=99: 1, c=4.00 \times 10^{-5} \mathrm{~mol} / \mathrm{L}\right.$, Figure $\left.4 \mathrm{c}\right)$. It is rationalized that the octadecane unit in (S)-3 serves as the crosslinking unit, leading to the formation of supramolecular polymeric networks (Figure 4a). It consequently leads to stronger gelation capability: the CGC value of (S)-3 was determined to be $2.47 \mathrm{mM}$ in $\mathrm{MCH} / \mathrm{TCE}(98: 2)$ (Figure 4a), which is approximately four times lower than that of $(S)-2$ $(10.9 \mathrm{mM})$ in pure $\mathrm{MCH}$.

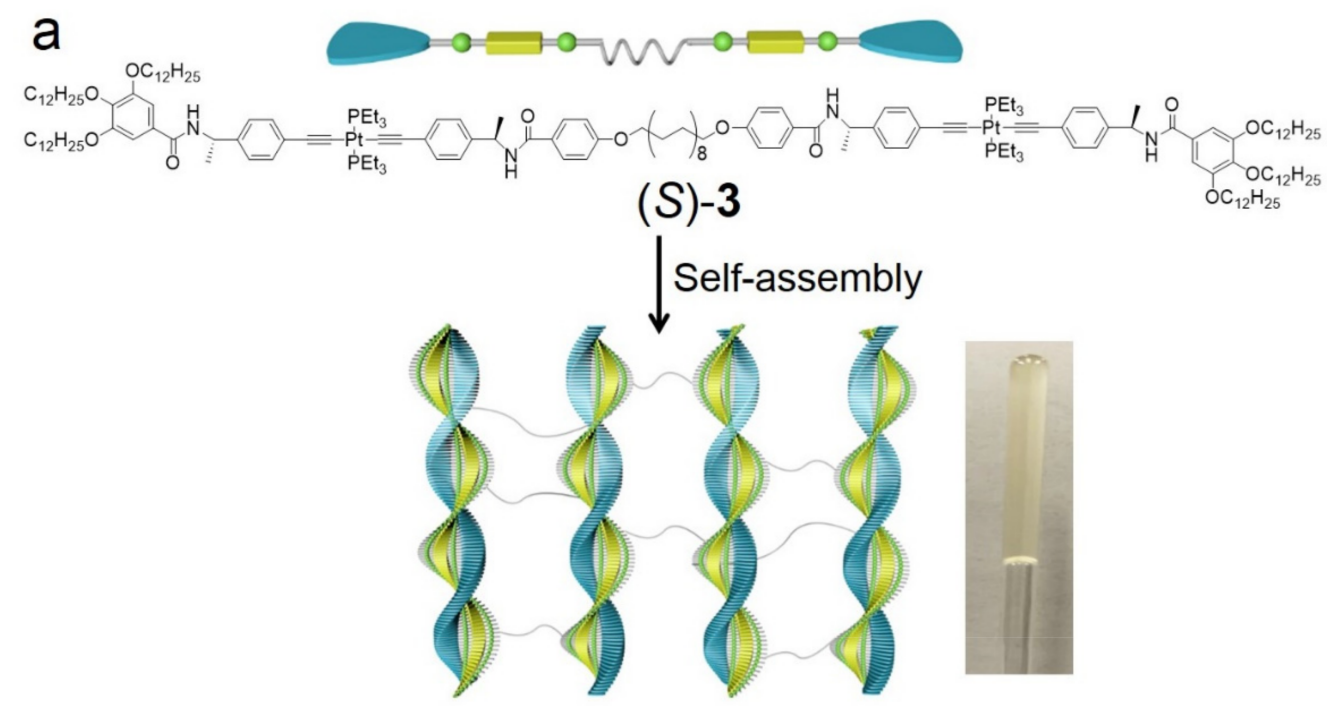

Supramolecular polymeric networks and gels
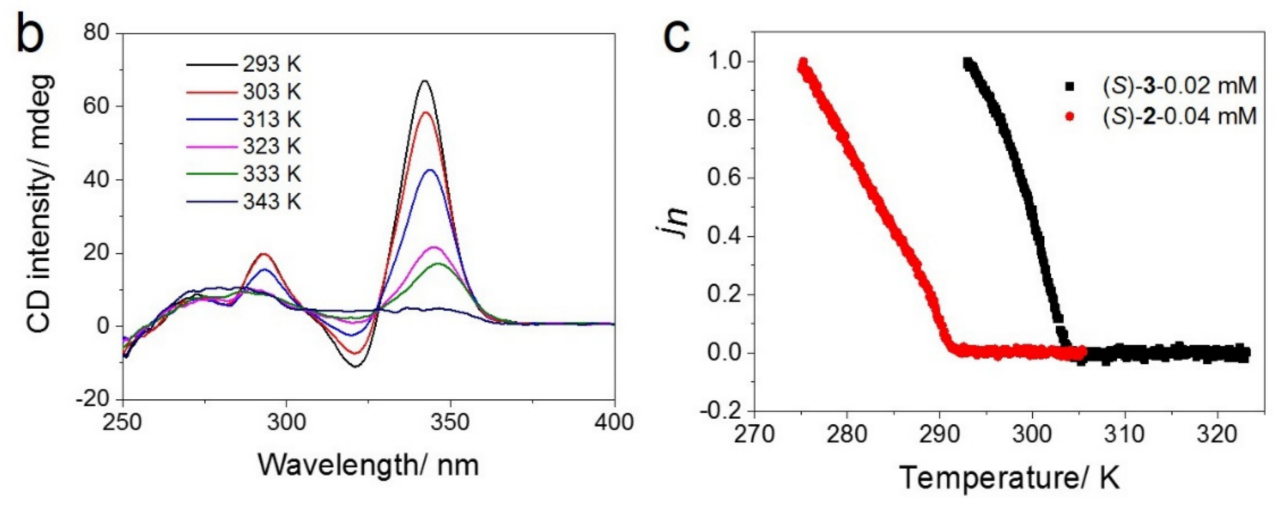

Figure 4. (a) Schematic representation for the construction of supramolecular polymeric networks and organogels derived from the ditopic monomer platinum(II) acetylide (S)-3. (b) CD spectra of (S)-3 at different temperatures in MCH/TCE $(99: 1, v / v, c=0.02 \mathrm{mM})$. (c) Net helicity $\varphi_{\mathrm{n}}$ as a function of temperature for (S)-3 (red line, $0.02 \mathrm{mM}, \lambda=342 \mathrm{~nm}$ ) and (S)-2 (black line, $0.04 \mathrm{mM}, \lambda=350 \mathrm{~nm}$ ) in $\mathrm{MCH} / \mathrm{TCE}(99: 1, v / v)$. 


\section{Discussion}

In summary, the amide linkage effects have been investigated, by comparing supramolecular polymerization behaviors of two structurally similar monomers $(S)-\mathbf{1}$ and (S)-2. Both of them undergo chiral supramolecular polymerization in apolar media via the nucleationelongation cooperative mechanism. Interestingly, as compared to the $\mathrm{N}$-phenyl benzamide linkages in (S)-1, $N-[(1 S)$-1-phenylethyl] benzamide linkages in (S)-2 give rise to effective chirality transfer behaviors, thanks to the closer distances between the chiral units and the platinum(II) acetylide rod. They also provide stronger intermolecular hydrogen bonding strength, which consequently brings higher thermo-stability and enhanced gelation capability for the resulting supramolecular polymers. Majority-rules effects are absent between $(S)-2$ and the enantiomer $(R)-2$, primarily ascribed to the large steric hindrance rendered by $N-[(1 S)-1$-phenylethyl] benzamide linkages around the chiral center. Moreover, supramolecular polymerization and gelation capabilities are further strengthened, by varying the structures from the monotopic monomer (S)-2 to ditopic one (S)-3. Therefore, the current study blooms new avenues for the rational design of supramolecular polymeric systems with tailored properties.

\section{Materials and Methods}

\subsection{Materials and Instruments}

$\mathrm{Pd}\left(\mathrm{PPh}_{3}\right)_{2} \mathrm{Cl}_{2}, \mathrm{CuI}$, potassium carbonate $\left(\mathrm{K}_{2} \mathrm{CO}_{3}\right)$ and (trimethylsilyl)acetylene were reagent grade and were employed as received. All chemical reagents and solvents are commercially available. ${ }^{1} \mathrm{H}-\mathrm{NMR}$ spectra were collected on a Ascend ${ }^{\mathrm{TM}} 400 \mathrm{MHz}$ spectrometer (Bruker, Karlsruhe, Germany) with trimethylsilane as the internal standard. ${ }^{13} \mathrm{C}$-NMR spectra were recorded on a Bruker Ascend ${ }^{\mathrm{TM}} 400 \mathrm{MHz}$ spectrometer at $101 \mathrm{MHz}$. Time-of-flight mass spectra (TOF-MS) were obtained on matrix-assisted laser desorption ionization-time of flight (autoflex speed TOF/TOF, Bruker). UV-vis spectra were recorded on a UV-1800 spectrometer (Shimadzu, Kyoto, Japan). CD measurements were performed on a J-1500 CD spectrometer (Jasco, Kyoto, Japan) equipped with a PFD-425S/15 Peltier-type temperature controller. The gel sample was transferred onto the plate at $298 \mathrm{~K}$. Oscillatory dynamic shear experiments were performed in the frequency range of $0.2-200 \mathrm{rad} \mathrm{s}^{-1}$, using a constant strain $(0.2 \%)$ determined with a strain sweep to lie within the linear viscoelastic regime.

\subsection{DFT Computations}

DFT computations were performed on the Gaussian 09, version D.01, software package (Wallingford, CT, USA). During the optimization process, nonmetallic atoms were described by the wb97xd/6-31G(d) computational level, while all platinum(II) atoms were described by the Lanl2dz effective core potential.

\subsection{Determination of the Assembling Thermodynamics for the Supramolecular Polymerization Process}

Compounds (S)-1, (S)-2 and (S)-3 adopt the cooperative supramolecular polymerization mechanism. Therefore, normalized UV - vis and CD melting curves were fitted with the Meijer-Schenning-van der Schoot mathematical model to obtain thermodynamic parameters in the supramolecular assembly process. In detail, the entire process can be divided into two separate steps: the nucleation and elongation regimes.

In the elongation regime, the fraction of aggregated molecules $\left(\varphi_{n}\right)$ is described by Equation (1):

$$
\varphi_{\mathrm{n}}=\varphi_{\mathrm{SAT}}\left\{1-\exp \left[\left(-h_{\mathrm{e}}\right) \times\left(T-T_{\mathrm{e}}\right) /\left(R \times T_{\mathrm{e}}^{2}\right)\right]\right\}
$$

In this equation, $h_{\mathrm{e}}$ denotes the molecular enthalpy release due to the non-covalent supramolecular polymerization, $T$ and $T_{\mathrm{e}}$ stand for the absolute temperature and elongation temperature, respectively. $R$ represents the universal gas constant. $\varphi_{\mathrm{SAT}}$ is a parameter that is introduced to prevent the relation $\varphi_{\mathrm{n}} / \varphi_{\mathrm{SAT}}$ surpassing the value of one. 


\subsection{Synthetic Procedures}

\subsubsection{Synthesis of $(S)-2$}

Compound 6 ( $250 \mathrm{mg}, 0.31 \mathrm{mmol})$, trans- $\mathrm{PtI}_{2}\left(\mathrm{PEt}_{3}\right)_{2}(85.0 \mathrm{mg}, 0.12 \mathrm{mmol})$ and $\mathrm{CuI}$ $(4.70 \mathrm{mg}, 0.20 \mathrm{mmol})$ were mixed in triethylamine $/ \mathrm{CH}_{2} \mathrm{Cl}_{2}(10 \mathrm{~mL}: 20 \mathrm{~mL})$ under a nitrogen atmosphere and stirred at room temperature for $24 \mathrm{~h}$. The solvents were evaporated on a rotary evaporator. The residue was purified by flash column chromatography (silica gel, $\mathrm{CH}_{3} \mathrm{OH} / \mathrm{CH}_{2} \mathrm{Cl}_{2}, 1: 99 \mathrm{v} / \mathrm{v}$ as the eluent) to provide (S)-2 as a yellow solid (210 $\left.\mathrm{mg}, 83 \%\right)$ ${ }^{1} \mathrm{H}-\mathrm{NMR}\left(400 \mathrm{MHz}, \mathrm{CDCl}_{3}, 298 \mathrm{~K}\right): \delta 7.19(\mathrm{~m}, 8 \mathrm{H}), 6.86(\mathrm{~s}, 4 \mathrm{H}), 6.07(\mathrm{~d}, J=7.7 \mathrm{~Hz}, 2 \mathrm{H}), 5.20$ $(\mathrm{m}, 2 \mathrm{H}), 3.91(\mathrm{~m}, 12 \mathrm{H}), 2.09(\mathrm{~m}, 12 \mathrm{H}), 1.70(\mathrm{~m}, 12 \mathrm{H}), 1.51(\mathrm{~d}, J=7.8 \mathrm{~Hz}, 6 \mathrm{H}), 1.38(\mathrm{~m}, 12 \mathrm{H})$, $1.30-1.17(\mathrm{~m}, 96 \mathrm{H}), 1.13(\mathrm{~m}, 18 \mathrm{H}), 0.81(\mathrm{t}, J=6.7 \mathrm{~Hz}, 18 \mathrm{H}) .{ }^{13} \mathrm{C}-\mathrm{NMR}\left(101 \mathrm{MHz}, \mathrm{CDCl}_{3}\right.$, $298 \mathrm{~K}): \delta 166.42,153.11,141.21,131.78,131.10,129.52,128.04,126.10,105.76,73.52,69.48$, $49.10,31.96,30.32,29.89-29.53,29.41,26.10,22.73,21.39,16.48,14.16,8.35$. MALDI-TOF $\left([\mathrm{M}+\mathrm{H}]^{+}\right): m / z 2033.9165$.

\subsubsection{Synthesis of (S)-3}

Compound $7(270 \mathrm{mg}, 0.20 \mathrm{mmol})$ and $\mathrm{CuI}(3.42 \mathrm{mg}, 0.02 \mathrm{mmol})$ were mixed in $\mathrm{Et}_{3} \mathrm{~N} / \mathrm{CH}_{2} \mathrm{Cl}_{2}(20 \mathrm{~mL}: 30 \mathrm{~mL})$ under a nitrogen atmosphere. Compound $8(71.0 \mathrm{mg}$, $0.09 \mathrm{mmol})$ in $\mathrm{CH}_{2} \mathrm{Cl}_{2}(10 \mathrm{~mL})$ was added dropwise to the reaction solution. After stirring at room temperature for $24 \mathrm{~h}$, the solvents were evaporated. The residue was purified by flash column chromatography (silica gel, $\mathrm{CH}_{3} \mathrm{OH} / \mathrm{CH}_{2} \mathrm{Cl}_{2}, 1: 99 \mathrm{v} / \mathrm{v}$ as the eluent) to provide (S)-3 as a yellow solid (210 $\mathrm{mg}, 72 \%)$. ${ }^{1} \mathrm{H}-\mathrm{NMR}\left(400 \mathrm{MHz}, \mathrm{CDCl}_{3}, 298 \mathrm{~K}\right): \delta 7.70(\mathrm{~d}$, $J=8.7 \mathrm{~Hz}, 4 \mathrm{H}), 7.31-7.17(\mathrm{~m}, 16 \mathrm{H}), 6.93(\mathrm{~s}, 4 \mathrm{H}), 6.88(\mathrm{~d}, J=8.7 \mathrm{~Hz}, 4 \mathrm{H}), 6.17(\mathrm{dd}, J=10.6$, $7.7 \mathrm{~Hz}, 4 \mathrm{H}), 5.26(\mathrm{~m}, 4 \mathrm{H}), 3.98(\mathrm{~m}, 16 \mathrm{H}), 2.17(\mathrm{~m}, 24 \mathrm{H}), 1.76(\mathrm{~m}, 16 \mathrm{H}), 1.66-1.52(\mathrm{~m}, 16 \mathrm{H})$, $1.47-1.23(\mathrm{~m}, 132 \mathrm{H}), 1.19(\mathrm{t}, J=8.0 \mathrm{~Hz}, 36 \mathrm{H}), 0.88(\mathrm{t}, J=6.7 \mathrm{~Hz}, 18 \mathrm{H}) .{ }^{13} \mathrm{C}-\mathrm{NMR}(101 \mathrm{MHz}$, $\left.\mathrm{CDCl}_{3}, 298 \mathrm{~K}\right): \delta 175.62,166.41,166.08,161.77,153.09,141.18,139.80,139.56,131.74,131.09$, $129.92,129.56,128.67,128.01,126.57,126.08,125.98,114.20,105.77,73.51,69.44,68.20,49.02$, $35.96,31.95,30.32,29.93-29.50,29.39,29.27,29.16,27.23,26.06,25.57,22.72,21.55,21.32$, $16.33,14.16,8.36$. MALDI-TOF $\left([\mathrm{M}+\mathrm{H}]^{+}\right): m / z 3240.7299$.

Supplementary Materials: The following are available online, Title 1: supramolecular polymerization behaviors of (S)-2 in apolar media; Title 2: comparison of supramolecular polymerization thermodynamics between $(S)-\mathbf{1}$ and $(S)$-2; Title 3: majority-rules for supramolecular polymers derived from $(S)-2 /(R)-2$; Title 4: supramolecular polymerization behaviors of (S)-3; Title 5: synthesis and structural characterization of (S)-2 and (S)-3.

Author Contributions: M.G. and F.W. designed and carried out the experiments. M.G., R.L., H.Z., and F.W. analyzed the data and wrote the manuscript. Y.H. performed the DFT calculations. H.Z. drew the cartoon pictures. All authors have read and agreed to the published version of the manuscript.

Funding: This work was supported by the National Natural Science Foundation of China (21922110, and 21871245), the Fundamental Research Funds for the Central Universities (WK3450000005), and the CAS Youth Innovation Promotion Association (Y201986).

Data Availability Statement: The data presented in this study are available included in the article and Supplementary Materials.

Acknowledgments: The DFT computations have been performed on the supercomputing center. We are grateful for the technical support from the High-Performance Computing Center of the University of Science and Technology of China.

Conflicts of Interest: The authors declare no conflict of interest.

Sample Availability: Samples of the compounds are available from the authors. 


\section{References}

1. Hoeben, F.; Jonkheijm, P.; Meijer, E.W. About supramolecular assemblies of $\pi$-conjugated systems. Chem. Rev. 2005, 4, 1491-1546. [CrossRef]

2. Aida, T.; Meijer, E.W.; Stupp, S.I. Functional supramolecular polymers. Science 2012, 335, 813-817. [CrossRef] [PubMed]

3. Jain, A.; George, S.J. New directions in supramolecular electronics. Mater. Today 2015, 18, 206-214. [CrossRef]

4. Hossain, M.; Sato, T.; Higuchi, M. A green copper-based metallo-supramolecular polymers: Synthesis, structure, and electrochromic properties. Chem. Asian J. 2013, 8, 76-79. [CrossRef] [PubMed]

5. Herbst, F.; Seiffert, S.; Binder, W. Dynamic supramolecular poly(isobutylene)s for self-healing materials. Polym. Chem. 2012, 3, 3084-3092. [CrossRef]

6. Busseron, E.; Ruff, Y.; Moulin, E.; Giuseppone, N. Supramolecular self-assemblies as functional nanomaterials. Nanoscale 2013, 5, 7098-7140. [CrossRef]

7. Praveen, V.; Vedhanarayanan, B.; Mal, A.; Ajayaghosh, A. Self-assembled extened $\pi$-systems for sensing and security applications. Acc. Chem. Res. 2020, 53, 496-507. [CrossRef]

8. Gershberg, J.; Fennel, F.; Rehm, T.; Lochbrunner, S.; Würthner, F. Anti-cooperative supramolecular polymerization: A new $\mathrm{K}_{2}-\mathrm{K}$ model applied to the self-assembly of perylene bisimide dye proceeding via well-defined hydrogen-bonded dimers. Chem. Sci. 2016, 7, 1729-1737. [CrossRef]

9. Greef, T.; Smulders, M.; Woffls, M.; Meijer, E.W. Supramolecular Polymerization. Chem. Rev. 2009, 109, 5687-5754. [CrossRef]

10. Wehner, M.; Würthner, F. Supramolecular polymerization through kinetic pathway control and living chain growth. Nat. Rev. Chem. 2020, 4, 38-53. [CrossRef]

11. Ikeda, T.; Lijima, T.; Sekiya, R.; Takahashi, O.; Haino, T. Cooperative self-assembly of carbazole derivatives driven by multiple dipole-dipole interactions. J. Org. Chem. 2016, 81, 6832-6837.

12. Ikeda, T.; Adachi, H.; Fueno, H.; Tanaka, K.; Haino, T. Induced-dipole-directed, cooperative self-assembly of a benzotrithiophene. J. Org. Chem. 2017, 82, 10062-10069.

13. Wagner, W.; Wehner, M.; Stepanenko, V.; Würthner, F. Supramolecular block copolymers by seeded living polymerization of perylene bisimides. J. Am. Chem. Soc. 2019, 141, 12044-12054. [CrossRef]

14. Chen, Z.; Xue, Y.; Gui, M.; Wang, F. Structural isomerism effect in platinum (II) acetylide-based supramolecular polymers. Inorg. Chem. 2020, 59, 6481-6488. [CrossRef]

15. Obert, E.; Bellot, M.; Bouteiller, L. Both water- and organo-soluble supramolecular polymer stabilized by hydrogen-bonding and hydrophobic interactions. J. Am. Chem. Soc. 2007, 129, 15601-15605. [CrossRef] [PubMed]

16. Singh, A.; Sun, S. Narcissistic self-sorting of hydrogen-bonded dimeric capsules formed through self-assembly of flexible tripodal receptors in polar solvents. Chem. Commun. 2012, 48, 7392-7394. [CrossRef] [PubMed]

17. Rao, M.; Sun, S. Supramolecular assemblies of amide-derived organogels featuring rigid $\pi$-conjugated phenylethynyl frameworks. Langmuir 2013, 29, 15146-15158. [CrossRef] [PubMed]

18. Chen, Y.; Zhu, B.; Zhang, F.; Han, Y.; Bo, Z. Hierarchical supramolecular self-assembly of nanotubes and layered sheets. Angew. Chem. Int. Ed. 2008, 47, 6015-6018. [CrossRef] [PubMed]

19. Hirano, K.; Ikeda, T.; Fujii, N.; Hirao, T.; Nakamura, M.; Haino, T. Helical assembly of a dithienogermole exhibiting switchable circularly polarized luminescence. Chem. Commun. 2019, 55, 10607-10610. [CrossRef]

20. Yuan, W.; Cheng, J.; Li, X.; Wu, M.; Han, Y.; Yan, C.; Zou, G.; Chen, Y. 5,6,12,13-Tetraazaperopyrenes as unique photonic and mechanochromic fluorophores. Angew. Chem. Int. Ed. 2020, 59, 9940-9945. [CrossRef]

21. Han, Y.; Zhu, B.; Chen, Y.; Bo, Z.; Chen, Y. Amphiphilic dendrons with a pyrene functional group at the focal point: Synthesis, self-assembly and generation-dependent DNA condensation. Polym. Chem. 2017, 8, 4798-4804. [CrossRef]

22. Greciano, E.; Calbo, J.; Buendía, J.; Cerdá, J.; Aragó, J.; Ortí, E.; Sánchez, L. Decoding the consequences of increasing the size of self-assembling tricarboxamides on chiral amplification. J. Am. Chem. Soc. 2019, 141, 7463-7472. [CrossRef]

23. García, F.; Aparicio, F.; Fernández, G.; Sánchez, L. Solvophbic effects in the self-assembly of triangular-shape amphiphilic oligo (phenylene ethynylenes). Org. Lett. 2009, 11, 2748-2751. [CrossRef]

24. Aparicio, F.; García, F.; Fernández, G.; Matesanz, E.; Sánchez, L. Mirror Helices and helicity switch at surfaces based on chiral triangular-shape oligo (phenylene ethynylenes). Chem. Eur. J. 2011, 17, 2769-2776. [CrossRef]

25. Greciano, E.; Calbo, J.; Ortí, E.; Sánchez, L. N-annulated perylene bisimides to bias the differentiation of metastable supramolecular assemblies into J- and H-aggregates. Angew. Chem. Int. Ed. 2020, 132, 17670-17677. [CrossRef]

26. Wagner, W.; Wehner, M.; Stepanenko, V.; Würthner, F. Impact of molecular shape on supramolecular copolymer synthesis in seeded living polymerization of perylene bisimides. CCS Chem. 2019, 1, 598-613. [CrossRef]

27. Iavicoli, P.; Xu, H.; Feldborg, L.; Linares, M.; Paradinas, M.; Ocal, C.; Casado, J.; Lazzaroni, R.; Feyter, S.; Amabilino, D. Tuning the supramolecular chirality of one- and two-dimensional aggregates with the number of stereogenic centers in the component porphyrins. J. Am. Chem. Soc. 2010, 132, 9350-9362. [CrossRef]

28. Moreira, L.; Calbo, J.; Nierengarten, J. Conjugated porphyrin dimers: Cooperative effects and electronic communication in supramolecular ensembles with $\mathrm{C}_{60}$. J. Am. Chem. Soc. 2016, 138, 15359-15367. [CrossRef] [PubMed]

29. Oliveras-G, C.; Meo, F.; González-C, A.; Beljonne, D.; Norman, P.; Linares, M.; Amabilino, D. Bottom-up hierarchical self-assembly of chiral porphyrins through coordination and hydrogen bonds. J. Am. Chem. Soc. 2015, 137, 15795-15808. [CrossRef]

30. Amabilino, D.; Smith, D.; Steed, J. Supramolecular materials. Chem. Soc. Rev. 2017, 46, 2404-2420. [CrossRef] 
31. Ikeda, T.; Hirano, K.; Haino, T. A circularly polarized luminescent organogel based on a Pt (II) complex possessing phenylisoxazoles. Mater. Chem. Front. 2018, 2, 468-474.

32. Chang, K.; Lin, J.; Shen, Y.; Hung, C.; Chen, C.; Sun, S. Synthesis and photophysical properties of self-assembled metallogels of platinum (II) acetylide complexes with elaborate long-chain pyridine-2,6-dicarboxamides. Chem. Eur. J. 2012, 18, 1312-1321. [CrossRef]

33. Gao, Z.; Zhu, J.; Han, Y.; Wang, F. Ligand effects on cooperative supramolecular polymerization of platinum (II) acetylide complexes. Polym. Chem. 2016, 7, 5763-5767. [CrossRef]

34. Camerel, F.; Ziessel, R.; Donnio, B.; Bourgogne, C.; Guillon, D.; Schmutz, M.; Iacovita, C.; Bucher, J.-P. Formation of Gels and Liquid Crystals Induced by Pt...Pt and $\pi-\pi *$ Interactions in Luminescent $\sigma$-Alkynyl Platinum (II) Terpyridine Complexes. Angezw. Chem. Int. Ed. 2007, 46, 2659-2662. [CrossRef]

35. Chang, K.; Chen, C.; Lin, T.; Ku, P.; Chen, C.; Wang, C.; Lin, H.; Tseng, M.; Singh, A.; Sun, S. Platinum (II)-directed self-assembly loop complexes for anion recognition and sensing. J. Chin. Chem. Soc. 2018, 65, 141-148. [CrossRef]

36. Yakuphanoglu, F.; Dagdelen, F.; Aydogdu, Y.; Aydogdu, A.; Sekerci, M. Electrical and optical properties of semiconducting metal complexes. Mater. Lett. 2003, 57, 3330-3340. [CrossRef]

37. Monzon, L.; Burke, F.; Coey, J.M.D. Optical, magnetic, electrochemical, and electrical properties of 8-hydroxyquinoline-based complexes with $\mathrm{Al}^{3+}, \mathrm{Cr}^{3+}, \mathrm{Mn}^{2+}, \mathrm{Co}^{2+}, \mathrm{Ni}^{2+}, \mathrm{Cu}^{2+}$, and $\mathrm{Zn}^{2+}$. J. Phys. Chem. C 2011, 115, 9182-9192. [CrossRef]

38. Han, Y.; Gao, Z.; Wang, C.; Zhong, R.; Wang, F. Recent progress on supramolecular assembly of organoplatinum (II) complexes into long-range ordered nanostructures. Coordin. Chem. Rev. 2020, 414, 213300. [CrossRef]

39. Tang, J.; Sun, Y.; Gong, Z.; Li, Z.; Zhou, Z.; Wang, H.; Li, X.; Saha, M.; Zhong, Y.; Stang, P.J. Temperature-responsive fluorescent organoplatinum (ii) metallacycles. J. Am. Chem. Soc. 2018, 140, 7723-7729. [CrossRef]

40. Tian, Y.; Meijer, E.W.; Wang, F. Cooperative self-assembly of platinum (II) acetylide complexes. Chem. Commun. 2013, 49, 9197-9199. [CrossRef]

41. Mauro, M.; Aliprandi, A.; Septiadi, D.; Kehr, N.; Cola, L. When self-assembly meets biology: Luminescent platinum complexes for imaging applications. Chem. Soc. Rev. 2014, 43, 4144-4166. [CrossRef]

42. Wang, X.; Han, Y.; Liu, Y.; Zou, G.; Gao, Z.; Wang, F. Cooperative supramolecular polymerization of fluorescent platinum acetylides for optical waveguide applications. Angew. Chem. Int. Ed. 2017, 56, 12466-12470. [CrossRef] [PubMed]

43. Gao, Z.; Han, Y.; Wang, F. Cooperative supramolecular polymers with anthracene-endoperoxide photo-switching for fluorescent anti-counterfeiting. Nat. Commun. 2018, 9, 3977. [CrossRef] [PubMed]

44. Ye, Q.; Zheng, F.; Zhang, E.; Bisoyi, H.; Zheng, S.; Zhu, D.; Lu, Q.; Zhang, H.; Li, Q. Solvent polarity driven helicity inversion and circularly polarized luminescence in chiral aggregation induced emission fluorophores. Chem. Sci. 2020, 11, 9989-9993. [CrossRef]

45. Cardolaccia, T.; Li, Y.; Schanze, K. Phosphorescent platinum acetylide organogelators. J. Am. Chem. Soc. 2008, 130, 2535-2545. [CrossRef]

46. Nguyen, M.; Wong, C.; Yip, J.H.K. Ligand perturbations on fluorescence of dinuclear platinum complexes of 5, 12diethynyltetracene: A spectroscopic and computational study. Organometallics 2013, 32, 1620-1629. [CrossRef]

47. Lee, C.; Grenier, C.; Meijer, E.W.; Schening, A.P.H.J. Preparation and characterization of helical self-assembled nanofibers. Chem. Soc. Rev. 2009, 38, 671-683. [CrossRef] [PubMed]

48. Dorca, Y.; Greciano, E.; Valera, J.; Gómez, R.; Sánchez, L. Hierarchy of asymmetry in chiral supramolecular polymers: Toward functional, helical supramolecular structures. Chem. Eur. J. 2019, 25, 5848-5864. [CrossRef]

49. Wolffs, M.; George, S.; Meskers, S.; Schenning, A.P.H.J.; Meijer, E.W. Macroscopic origin of circular dichroism effects by alignment of self-assembled fibers in solution. Angew. Chem. Int. Ed. 2007, 46, 8203-8205. [CrossRef]

50. Stals, P.J.M.; Smulders, M.M.J.; Palmans, A.R.A.; Meijer, E.W. Asymmetrically substituted benzene-1, 3, 5-tricarboxamides self-assembly and odd-even effects in the solid state and in dilute solution. Chem. Eur. J. 2009, 15, 2071-2080. [CrossRef] [PubMed]

51. Roosma, J.; Mes, T.; Leclère, P.; Palmans, A.R.A.; Meijer, E.W. Probing the solvent-assisted nucleation pathway in chemical self-assembly. Science 2006, 313, 80-83. [CrossRef]

52. Wilson, A.J.; Masuda, M.; Sijbesma, R.P.; Meijer, E.W. Supramolecular materials from benzene 1, 3, 5-tricarboxamide -based nanorods. J. Am. Chem. Soc. 2008, 130, 1120-1121. [CrossRef]

53. Wilson, A.J.; Masuda, M.; Sijbesma, R.P.; Meijer, E.W. Chiral amplification in the transcription of supramolecular helicity into a polymer backbone. Angew. Chem. Int. Ed. 2005, 44, 2275-2279. [CrossRef] [PubMed]

54. Palmans, A.R.A.; Meijer, E.W. Amplification of chirality in dynamic supramolecular aggregates. Angew. Chem. Int. Ed. 2007, 46, 8948-8968. [CrossRef] [PubMed]

55. Roman, M.; Cannizzo, C.; Pinault, T.; Isare, B.; Andrioletti, B.; Schoot, P.; Bouteiller, L. Supramolecular balance: Using cooperativity to amplify weak interactions. J. Am. Chem. Soc. 2010, 132, 16818-16824. [CrossRef]

56. Cao, H.; Feyter, S. Amplification of chirality in surface-confined supramolecular bilayers. Nat. Commun. 2018, 9, 3416. [CrossRef]

57. Smulders, M.; Stals, P.; Mes, T.; Paffen, T.; Schenning, P.H.J.; Palmans, A.R.A.; Meijer, E.W. Probing the limits of the majority-rules principle in a dynamic supramolecular polymer. J. Am.Chem. Soc. 2010, 132, 620-626. [CrossRef]

58. Smulders, M.; Filot, I.; Leenders, J.; Schoot, P.; Palmans, A.R.A.; Schenning, P.H.J.; Meijer, E.W. Tuning the extent of chiral amplification by temperature in a dynamic supramolecular polymer. J. Am. Chem. Soc. 2010, 132, 611-619. [CrossRef]

59. Shang, X.; Song, I.; Han, M.; Lee, J.; Ohtsu, H.; Choi, W.; Kim, J.; Ahn, J.; Kwak, S.; Oh, J. “Majority-rules” effect on supramolecular chirality and optoelectronic properties of chiral tetrachloro-perylene diimides. Adv. Opt. Mater. 2021, 9, 2001911. [CrossRef] 
60. Veld, M.; Haveman, D.; Palmans, A.R.A.; Meijer, E.W. Sterically demanding benzene-1,3,5-tricarboxamides: Tuning the mechanisms of supramolecular polymerization and chiral amplification. Soft Matter 2011, 7, 524-531. [CrossRef]

61. Helmich, F.; Smulders, M.; Lee, C.C.; Schenning, P.H.J.; Meijer, E.W. Effect of stereogenic centers on the self-sorting, depolymerization, and atropisomerization kinetics of porphyrin-based aggregates. J. Am. Chem. Soc. 2011, 133, 12238-12246. [CrossRef] [PubMed]

62. Narayan, B.; Bejagam, K.; Balasubramanian, S.; George, S. Autoresolution of segregated and mixed p-n stacks by stereoselective supramolecular polymerization in solution. Angew. Chem. Int. Ed. 2015, 54, 13053-13057. [CrossRef] [PubMed] 